\title{
Empirical Study on the Calendar Effect of CSI 300 Stock Index Futures
}

\author{
Wei Li \\ School of Economics \& Management \\ Nanjing University of Science and Technology \\ Nanjing, China
}

\begin{abstract}
This paper aims to study the calendar effects of CSI 300 stock index futures, taking the trading data of CSI 300 Index futures contracts as samples, and do empirical analysis with the least squares regression method and GARCH model. The results show that: the logarithmic return rate of CSI 300 index futures has obvious week effects, including a negative effect on Monday and a positive effect on Friday; the rate of turnover change has obvious week effects, the specific performances are the negative effect on Monday and the positive effect on Thursday; the rate of position change has significant week effects, showing a negative effect on Tuesday and a positive effect on Friday. This paper argues that the calendar effects can be explained from the perspective of the non-effective market and behavioral finance.
\end{abstract}

Keywords-calendar effect; dummy variable regression; GARCH-Model

\section{INTRODUCTION}

In April 2010, China Financial Futures Exchange launched stock index futures at the first time, which was based on CSI 300 Index, so it was called CSI 300 stock index futures. The introduction of stock index futures has increased the types of trading products in China's financial market, and expanded the products involved in the futures market. It not only promoted the development of China's futures market, but also played an important role in the development and maturity of China's financial market.

The calendar effect belongs to the securities market vision, which means that the market yield or volatility is significantly different from the rest of the trading day. The calendar effect often persists and can be divided into seasonal effects, monthly effects, week effects, and intraday effects. A large number of scholars at home and abroad have confirmed the existence of the calendar effect through empirical research. Domestic scholars have done a lot of research on the calendar effect. The samples are mainly from financial markets such as stock market and commodity futures market as well as foreign exchange market. The short-selling of stock index futures is short and the transaction data is small. Therefore, there is relatively little research on the calendar effect of stock index futures.

This paper mainly studies the week effect of CSI 300 stock index futures, and uses the daily closing data to analyze the three indicators of the yield, volume and position of CSI 300 stock index futures, draw conclusions and try to explain the calendar effect through non-effective market and behavioral finance and other aspects. Finally, relevant policy and investment recommendations are put forward.

\section{THEORETICAL ANALYSIS}

\section{A. Efficient Market Hypothesis}

In 1970, Eugene F. Fama first proposed efficient market hypothesis. He defines an efficient market in such a way that in a financial market, the price of a financial product contains all relevant information. According to the information contained in the stock price, the efficient markets are divided into three forms: one is weak form market, the stock price only contains historical transaction data and information; the other is semi-strong form market, the stock price not only contains historical transaction information, but also reflects the company's profitability, mergers and acquisitions and other information sets ; the third is strong form market, the stock price reflects all the information contained in the weak and semi-strong, and contains inside information.

The hypothetical premise of traditional finance theory is that the market is efficient, but as more and more scholars discover and empirically prove the existence of calendar effect, closed-end fund discount effect, and herding effect, the efficient market hypothesis has also been challenged.

\section{B. Behavioral Finance}

Behavioral finance uses financial market transaction data to study people's trading behaviors, abandoning the hypothesis of "rational people" in traditional finance, and using some theories of psychology and sociology to explain some behaviors of investors in real life.

Behavioral finance has two main theoretical pillars. One of the pillars is the limitation of arbitrage. Arbitrage pricing theory believes that due to the existence of arbitrageurs, market prices tend to be fair, thus ensuring the efficiency of financial markets. However, behavioral financiers hold different views. They believe that in real life, due to the existence of arbitrage costs and risks, the market often cannot guarantee its full efficiency through arbitrage. The second pillar is the limited nature of human reason. Investors 
in the financial market are not completely rational. Their investment decisions are often influenced by their own cognitive abilities and personal emotions, which leads to investment behaviors that are contrary to market trends. The irrational characteristics of investors mainly include overconfidence, loss of disgust, and herding effect.

\section{RESEARCH DESIGN}

\section{A. Sample Selection and Data Source}

This paper selects the closing date of the trading day of the main contract of CSI 300 stock index futures as a sample to study its calendar effect. In the study of the week effect, the 983-day closing data for the four years from 2012.1.42016.1.20 was used as the research sample. The data source is the Wind database. This article uses Eviews7.0 and excels to process data.

The research object of this paper is the main contract of CSI 300 stock index futures. The main contract standard is the futures contract with the largest transaction value after the stock index futures market closes on the historical day. This paper selects the rate of return, the rate of change of volume and the rate of change of positions as the metrics to statistically process the sample data. There are two ways to calculate yield: percentage yield and $\log$ yield. In this paper,

the logarithmic rate of return $r_{t}$ is used as a measure when studying the week effect:

$$
r_{\mathrm{t}}=\operatorname{In}\left(P_{t}\right)-\operatorname{In}\left(P_{t-1}\right)
$$

The volume change rate:

$$
d v c r_{t}=\left(v c r_{t}-v c r_{t-1}\right) / v c r_{t-1}
$$

The position change rate:

$$
d p c r_{t}=\left(p c r_{t}-p c r_{t-1}\right) / p c r_{t-1}
$$

\section{B. Research Model}

This paper uses multiple regression models for empirical research. In the process of multiple regressions, dummy variables are added to test the calendar effect of CSI 300 stock index futures. The week effect is essentially a significant difference in the rate of return or volatility during the week. This paper uses Eviews7.0 to examine the week effect from three aspects: descriptive statistical analysis, virtual variable multiple regression model and GARCH model.

In this paper, the study of the week effect is specifically to study if there is significant difference in the five trading days of the week in the three indicators of the rate of return, the rate of change of the volume and the rate of change of the position, so the virtual variables are set to exclude other time. In this paper, the daily yield data of 2012.1.4-2016.1.20 for the week effect are selected, and the dummy variable regression model and the GARCH model is used to test the week effect of CSI 300 stock index futures. The regression model with five dummy variables had been established which are selected corresponding to five working days, and without constant items. The regression equation is established as follows:

$$
r_{t}=\alpha_{1} w_{1}+\alpha_{2} w_{2}+\alpha_{3} w_{3}+\alpha_{4} w_{4}+\alpha_{5} w_{5}+\varepsilon_{t}
$$

Among them, ${ }^{r}{ }_{t}$ represents the logarithmic daily return rate of the CSI 300 stock index futures, $\alpha$ indicates the coefficient, $\mathrm{W}$ is the dummy variable, and $\varepsilon$ is the error term. When $\mathrm{t}$ is Monday, $\mathrm{W} 1=1, \mathrm{~W} 2, \mathrm{~W} 3, \mathrm{~W} 4, \mathrm{~W} 5$ are all zero, other cases and so on.

First, descriptive statistics are performed on the three indicator sequences, and then the stationarity, autocorrelation, and $\mathrm{ARCH}$ effects of the time series are tested. If there is no $\mathrm{ARCH}$ effect in the sequence, the result is directly obtained by the virtual variable least squares regression method. If the sequence has the ARCH effect, the GARCH model is considered for fitting.

\section{EMPIRICAL RESULT}

\section{A. Descriptive Statistics}

Firstly, the researchers use Eviews to make a descriptive analysis of the three indicators of the daily logarithmic yield, the volume change rate and the change rate of the position of CSI 300 stock index futures.

TABLE I. Statistical CharaCteristics AND Distribution OF DAILy RETURN RATE OF CSI 300 STOCK INDEX FutURES

\begin{tabular}{|c|l|l|l|l|c|}
\hline & Mean & Maximum & Minimum & Std. Dev & $\begin{array}{c}\text { JB } \\
\text { statistics }\end{array}$ \\
\hline Mon. & -0.0020 & 0.0694 & -0.1022 & 0.0231 & 215.5264 \\
\hline Tues. & 0.0004 & 0.0875 & -0.1044 & 0.0199 & 568.0126 \\
\hline Wed. & 0.0006 & 0.0616 & -0.0764 & 0.0163 & 178.1993 \\
\hline Thur. & 0.0010 & 0.0974 & -0.0678 & 0.0204 & 289.6001 \\
\hline Fri. & 0.0012 & 0.0895 & -0.0852 & 0.0190 & 233.7041 \\
\hline
\end{tabular}

It can be seen from "Table I" that the daily logarithmic yield of CSI 300 stock index futures from January 4, 2012 to January 20, 2016 on Monday is negative, and the rest are positive returns. As can be seen from the standard deviation, the standard deviation on Monday is 0.0231 , and the standard deviation on Thursday is 0.0204 , which is significantly greater than the standard deviation on Tuesday, Wednesday and Friday, indicating that yields on Monday and Thursday fluctuate more than other dates. 


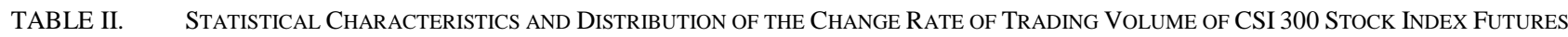

\begin{tabular}{|c|l|l|l|l|l|}
\hline & \multicolumn{1}{|c|}{ Mean } & Maximum & Minimum & Std. Dev & $\begin{array}{c}\text { JB } \\
\text { statistics }\end{array}$ \\
\hline Mon. & -0.0505 & 0.8081 & -0.9360 & 0.2212 & 38.7804 \\
\hline Tues. & 0.0398 & 0.7637 & -0.7099 & 0.2461 & 5.2244 \\
\hline Wed. & -0.0064 & 1.0811 & -0.7271 & 0.2463 & 40.6790 \\
\hline Thur. & 0.0857 & 1.6252 & -0.8835 & 0.3433 & 196.3788 \\
\hline Fri. & 0.1190 & 3.0740 & -0.4651 & 0.3845 & 2778.469 \\
\hline
\end{tabular}

As shown in "Table II", the average value on Monday and Wednesday is negative, and the average on Tuesday, Thursday and Friday is positive. Monday's volume change rate has the lowest average value of -0.050505 . The volume change rate on Friday was the highest at 0.118986 . As for the standard deviation, the standard deviations on Thursday and Friday were 0.3433 and 0.3845 , respectively, which were greater than the standard deviation of other dates, indicating that the volume change rate fluctuated significantly on Thursday and Friday.

TABLE III. Statistical Characteristics AND Distribution of THE CHANGE RATE OF Positions OF CSI 300 STOCK INDEX Futures

\begin{tabular}{|c|l|l|l|l|l|}
\hline & Mean & Maximum & Minimum & Std. Dev & $\begin{array}{c}\text { JB } \\
\text { statistics }\end{array}$ \\
\hline Mon. & -0.0087 & 0.2292 & -0.3456 & 0.0807 & 38.4693 \\
\hline Tues. & -0.0376 & 0.8921 & -0.3630 & 0.1290 & 1960.638 \\
\hline Wed. & 0.0120 & 1.1669 & -0.5641 & 0.2385 & 638.0537 \\
\hline Thur. & 0.0704 & 2.7445 & -0.7169 & 0.3835 & 2845.623 \\
\hline Fri. & 0.1030 & 4.8669 & -0.1696 & 0.5549 & 12289.67 \\
\hline
\end{tabular}

As can be seen from the above "Table III", the average change rate of the positions of CSI 300 stock index futures on Monday and Tuesday is negative, and on Wednesday, Thursday and Friday is positive. The lowest is on Tuesday at -0.037590 , and the highest on Friday is 0.103002. In terms of the standard deviation, Friday's standard deviation is the largest, 0.5549, and the standard deviation on Monday is the smallest, 0.0807 .

\section{B. Stationarity Test}

The test of stationarity of financial time series is crucial for subsequent research. Only the sequence is stable, the statistical features of the sequence estimated from past data can be applied to the prediction of changes in the future period of the sequence. In this paper, the self-correlation function and autocorrelation graph are used to judge the sequence Stationarity, and the ADF unit root test is used to test the Stationarity of return rate and the volume change rate and the position change rate.

TABLE IV. The Results OF THE STATIONARITY TEST OF CSI 300 STOCK INDEX FUTURES

\begin{tabular}{|c|c|}
\hline & \multicolumn{1}{|c|}{ ADF } \\
\hline Rate of Return & -24.2435 \\
\hline Volume Change Rate & -27.1073 \\
\hline Position Change Rate & -25.5161 \\
\hline
\end{tabular}

It can be seen from "Table IV" above that the ADF value of the yield series is -24.2435 , the $\mathrm{ADF}$ value of the volume change rate sequence is -27.1073 , and the ADF value of the position change rate sequence is -25.5161 , all less than the value at $1 \%$ significant level. Therefore, the non-stationary null hypothesis of the sequence is rejected, and the conclusion can be drawn that the logarithmic rate of return sequence, the volume change rate sequence and the position change rate sequence have no unit root and are stable.

\section{Autocorrelation Test and ARCH Effect Test}

Financial time series often have hysteresis, that is, one factor not only affects the current variables, but also affects the variables of the next period. This paper uses Eviews to generate 20-order autocorrelation and partial autocorrelation plots to test the autocorrelation of CSI 300 stock index futures yield, volume change rate and position change rate series. The results show that there is no autocorrelation between the daily logarithmic rate of return and the daily position rate of CSI 300 stock index futures, and there is a first-order autocorrelation of the daily trading volume change rate.

First, the Eviews is used to generate the autocorrelation graph of the residual squared sequence of the logarithmic rate of return, the rate of change of the volume and the rate of change of the position of CSI 300 stock index futures. According to the order of the truncated autocorrelation function, the lag period of the ARCH LM test is defined. The lag period of the ARCH LM test determined by the above three residual square sequence autocorrelation plots is 4,1 , and 1 , respectively. The test results are as follows: (see "Table V", "Table VI", and "Table VII")

TABLE V. ARCH LM TEST RESUlt OF DAILY RETURN RATE OF CSI 300 STOCK INDEX FUTURES

\begin{tabular}{|c|c|c|c|}
\hline F-statistic & 62.25538 & Prob.F(4,974) & 0.0000 \\
\hline Obs*R-squared & 199.3359 & Prob.Chi-Square(4) & 0.0000 \\
\hline
\end{tabular}


TABLE VI. ARCH LM TEST RESUlT OF THE CHANGE RATE OF TRADING VOLUME OF CSI 300 STOCK INDEX FUTURES

\begin{tabular}{|c|c|c|c|}
\hline F-statistic & 7.341318 & Prob.F(1,980) & 0.0069 \\
\hline Obs*R-squared & 7.301603 & Prob.Chi-Square(1) & 0.0069 \\
\hline
\end{tabular}

TABLE VII. ARCH LM TEST RESULT OF THE CHANGE RATE OF POSITIONS OF CSI 300 STOCK INDEX FUTURES

\begin{tabular}{|c|c|c|c|}
\hline F-statistic & 0.681751 & Prob.F(1,980) & 0.4092 \\
\hline Obs*R-squared & 0.682668 & Prob.Chi-Square(1) & 0.4087 \\
\hline
\end{tabular}

In the ARCH LM test, the existence of the ARCH effect is mainly through the P-value of the F statistic and the chisquare statistic. It can be seen from the above tables that, the ARCH LM test F statistic and the chi-square statistical probability $\mathrm{P}$ value of the daily logarithmic rate of return and the volume change rate of CSI 300 stock index futures are less than 0.01, so the original hypothesis cannot be accepted and the original sequence has an $\mathrm{ARCH}$ effect. In the $\mathrm{ARCH}$ $\mathrm{LM}$ test of the change rate of positions, the probability $\mathrm{P}$ value of the $\mathrm{F}$ statistic and the chi-square statistic are both greater than 0.05 . Therefore, the original hypothesis is accepted, that is, the original sequence has no $\mathrm{ARCH}$ effect.

\section{Regression Result}

Based on the above analysis, this paper uses the GARCH $(1,1)$ model to perform the virtual variable regression on the daily logarithmic rate of return of the CSI 300 stock index futures, the $\mathrm{AR}(1)-\mathrm{GARCH}(1,1)$ model to virtualize the rate of change of the volume, and uses the least squares method (OLS) to perform a virtual variable regression on the rate of change in position. The statistical results are as follows:

TABLE VIII. REgRESSION STATISTICS OF THE WEEk EFFECT OF DAILY RETURN RATE OF CSI 300 STOCK INDEX FutURES

\begin{tabular}{|c|l|l|l|l|l|}
\hline & \multicolumn{1}{|c|}{ Mon. } & \multicolumn{1}{|c|}{ Tues. } & \multicolumn{1}{|c|}{ Wed. } & \multicolumn{1}{|c|}{ Thur. } & \multicolumn{1}{|c|}{ Fri. } \\
\hline Coefficient & -0.001377 & 0.000457 & 0.001043 & -0.00038 & 0.002368 \\
\hline Std. Dev & 0.000857 & 0.001130 & 0.001043 & 0.000935 & 0.000937 \\
\hline $\boldsymbol{Z}$ statistics & -1.606737 & 0.403874 & 1.000023 & -0.40176 & 2.528713 \\
\hline P value & 0.1081 & 0.6863 & 0.3173 & 0.6879 & 0.0114 \\
\hline
\end{tabular}

As can be seen from "Table VIII", the daily logarithmic yield of CSI 300 stock index futures during 2012.1.42016.1.20 was significantly negative on Monday, at 0.001377 , and was significantly positive on Friday at 0.002368 . $\mathrm{P}$ value on Monday is significant at $10 \%$, and $\mathrm{P}$ value on Friday is significant at $5 \%$, indicating that the logarithmic yield of CSI 300 stock index futures has week effect, which is characterized by a negative Monday effect and a positive Friday effect.

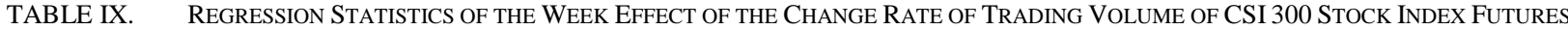

\begin{tabular}{|c|l|l|l|l|l|}
\hline & \multicolumn{1}{|c|}{ Mon. } & \multicolumn{1}{|c|}{ Tues. } & Wed. & Thur. & Fri. \\
\hline Coefficient & -0.058660 & 0.051712 & 0.013305 & 0.071594 & 0.059875 \\
\hline Std. Dev & 0.017929 & 0.014924 & 0.012997 & 0.013742 & 0.016811 \\
\hline Z statistics & -3.271841 & 3.464960 & 1.023725 & 5.209711 & 3.561591 \\
\hline P value & 0.0011 & 0.0005 & 0.3060 & 0.0000 & 0.0004 \\
\hline
\end{tabular}

It can be seen from "Table IX", the daily trading volume change rate of the CSI 300 stock index futures during the four years of 2012.1.4-2016.1.20 was the lowest on Monday at -0.058660 , and the highest on Thursday at 0.071594 . On Monday, the $\mathrm{P}$ value was 0.0011 , and on Thursday the $\mathrm{P}$ value was 0.0000 , and the coefficients were all significant at the $1 \%$ level. Therefore, it can be concluded that the trading volume change rate of CSI 300 stock index futures has a significant week effect, which is characterized by a negative Monday effect and a positive Thursday effect.

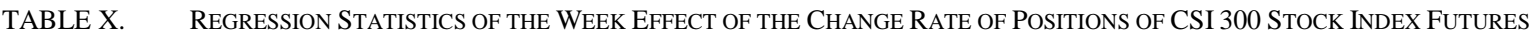

\begin{tabular}{|c|l|l|l|l|l|}
\hline & Mon. & Tues. & Wed. & Thur. & Fri. \\
\hline Coefficient & -0.008691 & -0.03759 & 0.012012 & 0.070359 & 0.103002 \\
\hline Std. Dev & 0.023454 & 0.023216 & 0.023157 & 0.023274 & 0.023394 \\
\hline Z statistics & -0.370543 & -1.61916 & 0.518725 & 3.023025 & 4.403001 \\
\hline P value & 0.7111 & 0.1057 & 0.6041 & 0.0026 & 0.0000 \\
\hline
\end{tabular}

As can be seen from "Table X", the change rate of positions of CSI 300 stock index futures during the four years of 2012.1.4-2016.1.20 was the lowest on Tuesday at 0.037590 and the highest on Friday at 0.103002 . The $\mathrm{P}$ value on Tuesday was 0.1057 , which was significant at the $10 \%$ level, and the $\mathrm{P}$ value on Friday was 0.0000 , which was significant at the $1 \%$ level. In summary, it is concluded that the rate of change in the position of CSI 300 stock index futures has a significant week effect, showing a negative Tuesday effect and a positive Friday effect.

\section{CONCLUSION}

This paper mainly studies the calendar effect of CSI 300 stock index futures, takes the main contract of CSI 300 stock index futures as the research object, and studies the week 
effect of the daily data logarithmic yield, volume and position. In this paper, the descriptive statistics of each index are firstly carried out, and then the stationarity test, autocorrelation test and $\mathrm{ARCH}$ effect test are carried out for each time series. Finally, the least squares multiple regression with dummy variables and GARCH $(1,1)$ model are used respectively. Conclusions are as follows:

- The average daily logarithmic yield rate of CSI 300 stock index futures for 2012.1.4-2016.1.20 was significantly negative on Monday at -0.001377 , and was significantly positive on Friday at 0.002368 . It shows that the logarithmic yield of CSI stock index futures has a week effect, which is characterized by a negative Monday effect and a positive Friday effect.

- The daily volume change rate was the lowest on Monday, at -0.058660 , and the highest on Thursday, at 0.071594 . During the week, only Monday was significantly negative, and Tuesday, Wednesday, Thursday and Friday were positive. This shows that investors will be more cautious at the beginning of the week, and then the trading volume will fluctuate. Therefore, it can be concluded that the trading volume change rate of CSI 300 stock index futures has a significant week effect, which is characterized by a negative Monday effect and a positive Thursday effect.

- The change in daily position volume was the lowest on Tuesday, at -0.037590 , and the highest on Friday, at 0.103002 . In summary, it is concluded that the rate of change in the position of CSI 300 stock index futures has a significant week effect, showing a negative Tuesday effect and a positive Friday effect.

The week effect of the yield rate may be due to incomplete information transmission at the beginning of the week. As the information spreads, the investors' investment is more reasonable, so there is a positive yield rate on Friday. The reason of the week effect of trading volume and position volume is that investors are cautious at the beginning of the week, but over-optimism or overconfidence on Thursday and Friday. As a result, the trading volume and position volume increase.

\section{REFERENCES}

[1] Fields, M. J.,"Stock Prices:A Problem in Verification", Journal of Business 4(October 1931), pp.415- 418.

[2] Cross, F.,"The Behavior of Stock Prices on Fridays and Mondays", Financial Analysts Journal(November-December 1973), pp.67- 69.

[3] French, K., "Stock Returns and the Weekend Effect",Journal ofFinancial Economics 8 (March 1980), pp.55-69.

[4] Gibbons, M. and P.Hess, "Day of the Week Effects and Asset Returnas", Journal of Business 54(October 1981), pp.579-596.

[5] Jaffe, J. and R. Westerfield, "The Week-End Effect in Common Stock Returns: The International Evidence", The Journal of Finance 40(June 1985), pp.433- 454

[6] Aggarwal, R. and P. Rivoli , "Seasonal and Day-of-the-Week Effects in Four Emerging Stock Markets", The Financial Review 24(November 1989), pp.541- 550.
[7] Dai Guoqiang and Lu Rong. The Week Effect Test of China's Stock Market. Financial Research [J]. 1999(4): 48-54

[8] Feng Licheng. The 'intra-week effect' of China's stock market Economic research [J]. 2000(11): 50-57.

[9] Chen Chao, Qian Ping. Re-testing the 'intra-week effect' of China's stock market. Economic Science [J]. 2002(1): 85-91.

[10] Shi Daimin. The intra-week effect of Shanghai stock market volatility. Research on quantitative economy technology economy [J]. 2003(6): 154-157.

[11] Chen Xiongbing, Zhang Zongcheng. An Empirical Study of China's Stock Market Returns and Fluctuation Effects Based on Modified GARCH Model. China Management Science [J]. 2008(8): 44-49.

[12] Guo Yanfeng,Wei Yu.Study on the Calendar Effect of the Index of Stock Index Futures in China [J]. Journal of Southwest Jiaotong University(Social Science Edition), 2007, 8(5)

[13] Li Jianqiang. Research on the Effect of China Futures Market on Sunday[J].Financial Economics, 2009(18): 84-86

[14] Fang Zhenming,Wang Chunfeng.Study on the Intraday Effect of the Return of Shanghai Stock Market [J]. Journal of Beijing Institute of Technology(Social Science Edition), 2004(3): 38-41

[15] Liu Xiangli, Cheng Siwei.Analysis of Intraday Effect of China Futures Market [J]. Systems Engineering Theory and Practice, 2008(8): 63-80

[16] Yin Shuangjian. Research on the Calendar Effect of Shanghai and Shenzhen 300 Stock Index Futures [D]. Guangdong: Jinan University, 2013 